\title{
ANALISIS PERILAKU MOBILITAS ANAK BUAH KAPAL (ABK) PELABUHAN PERIKANAN NUSANTARA (PPN) PENGAMBEN DESA PENGAMBENGAN KECAMATAN NEGARA KABUPATEN JEMBRANA
}

\author{
Dany Jafar Hermawan ${ }^{1}$, Putu Indra Christiawan ${ }^{*}$ \\ Program Studi Pendidikan Geografi, Universitas Pendidikan Ganesha, Indonesia
}

\author{
A R T I C L E I N F O \\ Article history: \\ Received 19 September \\ 2018 \\ Received in revised form \\ 6 November 2018 \\ Accepted 12 November \\ 2018 \\ Available online 30 \\ November 2018

Kata Kunci:
ABK
Mobilitas
Perilaku Mobilitas
Keywords:
The Crew
Mobility
Mobility Behavior.

\section{A B S T R A C T}

This study was conducted in Pengambengan Village with the aimed (1) to analyze the factors that influence the crew has mobility behavior of the PPN Pengambengan, (2) identify the characteristics of them, (3) and identify the distribution patterns of them. The design used in this study is descriptive qualitative research with data collection methods and document recording and analyzed using SPSS qualitative data analysis. The results showed that (1) factors that influence mobility behavior are driving factors $54.9 \%$, pulling factor $50.7 \%$, obstacles faktor $69.0 \%$. (2) characteristics crew with the most age range is $20-29$ years, married status $76.4 \%$ married. (3) The crew has mobility behavior is seen from the distribution of the area of origin which is dominated by the crew from Banyuwangi and intensity of returning to the area of origin the most dominant thing done by the crew were during the once a month.

\footnotetext{
* Corresponding author. 



\section{Pendahuluan}

Desa Pengambengan Kecamatan Negara Kabupaten Jembrana, sebagai wilayah pesisir sangatlah potensial untuk pembangunan sektor perikanan tangkap. Keberadaaan PelabuhanPerikanan Nusantara (PPN) Pengambengan yang berjarak $9 \mathrm{Km}^{2}$ dari Kota Negara dan $105 \mathrm{Km}^{2}$ dari Kota Denpasar dapat dikategorikan sebagai salah satu "outerring fishing port" (Kerangka Kelembagaan Pelabuhan Perikanan Lingkar Luar) dalam konteks pertumbuhan ekonomi wilayah (PIPP PP. Pengambengan).Berdirinya PPN Pengambengan sebagai pusat kegiatan perikanan masyarakat, diharapkan dapat menjadikan Desa Pengambengan mempunyai daya tarik tersendiri, yakni sebagai daerah dengan kegiatan sektor perikanan tangkap yang sekaligus berada pada lokasi pariwisata mancanegara Pulau Bali. Sehingga perikanan sebagai salah satu SDA yang mempunyai peranan penting dan strategis dalam pembangunan perekonomian nasional terutama dalam meningkatkan perluasan kesempatan kerja, pemerataan pendapatan dan peningkatan taraf hidup bangsa pada umumnya, nelayan kecil, pembudidaya ikan kecil dan pihak-pihak pelaku usaha di bidang perikanan dengan tetap memelihara lingkungan, kelestarian dan ketersediaan sumber daya (Retnowati, 2011).

Sektor perikanan memiliki peranan strategis dalam pembangunan nasional. Ditinjau dari potensi sumberdaya alam, Indonesia dikenal sebagai negara maritim terbesar di dunia karena memiliki potensi kekayaan sumberdaya perikanan yang relatif besar (Triarso, 2012). Kegiatan pada sektor perikanan tangkap di Desa Pengambengan telah dimulai sejak tiga puluhtahun lalu berupa Pangkalan Pendaratan Ikan (PPI) yang dibangun pada tahun 1976/1977, kemudian secara bertahap dikembangkan oleh Fisheries Infastructure Sector Project, setelah dilakukan studi kelayakan melalui Roger Consulting Marine Gmbh pada tahun 1988 (PIPP PP. Pengambengan). Tercatat ada 141 perusahaan yang berinvestasi dengan total tenaga kerja mencapai 5797 pegawai, kemudian PPN Pengambengan juga didukung oleh industri pengolahan ikan yang ada di komplek maupun yang ada di luar komplek pelabuhan, yaitu industri pengalengan ikan dan tempat penepungan ikan berjumlah 14 unit (diluar komplek pelabuhan), serta 1 unit industri di dalam komplek pelabuhan yaitu PT. Cilacap Samudra Fishing Industry yang kegiatannya berbentuk pengolahan ikan, pabrik es, cold storage dan galangan kapal (PIPP PP. Pengambengan). Tetapi tidak semua lapisan masyarakat nelayan dapat menikmati berkah modernisasi perikanan tersebut, terkait dengan ketersediaan modal ekonomi yang ada (Tain, 2011).

Nelayan PPN Pengambengan termasuk dalam katagori nelayan tradisional dengan hasil tangkapan utama yaitu berupa ikan lemuru yang terkonsentrasi di Selat Bali.Armada penangkap ikan yang dipakai nelayan pengambengan biasanya merupakan perahu tradisional asli Madura yang mempunyai bentuk kontruksi dasar berganda "double pointed" yakni lambung kiri dan lambung kanan bertemu dengan satu titik masing-masing di haluan dan buritan kapal (Santara, 2014). Jenis alat tangkap dominan yang dipakai oleh nelayan pengambengan adalah jaring pukat cincin dengan nama lokal slerek dimana operasi penangkapan ikan yang dilakukan menggunakan metode dua 
sistem perahu "two boat system"dengan pola kerja hariansatu hari perjalanan "one day trip", kemudian jumlah Anak Buah Kapal (ABK) perahu slerek biasanya berjumlah mencapai 20-35 orang (Santara, 2014). Keterbatasan kemampuan nelayan-nelayan tradisional dalam berbagai aspek, khususnya penguasaan alat tangkap yang serba terbatas adalah hambatan potensial bagi mereka untuk meningkatkan kesejahteraan sosial dan mengatasi kemiskinan yang membelit mereka selama ini (Suyanto, 2011).

PelabuhanPerikanan Nusantara (PPN) Pengambengan terdapat 127 perahu tradisional yang beroperasi dengan berbagai ukuran, mulai dari ukuran (menurut panjang perahu) $11 \mathrm{~m}$ hingga $21 \mathrm{~m}$. Banyaknya jumlah perahu yang melakukan kegiatan penangkapan ikan tersebut, diperkirakan akan membutuhkan banyak ABK agar kegiatan penangkapan dapat dilaksanakan sesuai dengan standar pengoprasinnya. Jumlah keseluruhanABK mencapai 2392 orang yang tersebar di masing - masing ukuran perahu yang berbeda - beda.

Banyaknya kebutuhan akan armada perahu tradisonal pada musim panen ikan menjadikan peningkatan pasar tenaga kerja khususnya ABK juga kian bertambah.Seiring bertambahnya kebutuhan akan ABK pada masing - masing perahu yang apabila hanya mencari di Desa Pengambengan saja maka tidak akan mencukupi, rata-rata nelayan pemilik perahu akan mencari ABK hingga ke luar Pulau Bali. Agar dapat dipekerjakan di perahu milik juragan perahu tertentu, mereka akan diberikan uang pengikat antara Rp. 500.000-, hingga Rp. 1.000.000-, dengan perjanjian tidak akan kabur dan pindah ke kapal lain yang memberikan uang pengikat lebih besar (Edy, 2017) Tingkat perekonomian mereka umumnya masih berada pada tataran subsisten, dengan pendapatan yang pas-pasan, dan berada di bawah pendapatan rata-rata kelompokkelompok masyarakat lainnya (Masyhuri, 2014).

Kenyataan yang menunjukan bahwa ABK mencapai 20 hingga 35 orang tiap perahu, maka dapat dipastikan sektor perikanan tangkap di desa Pengambengan mampu menyerap banyak tenaga kerja termasuk ABK dari luar daerah. Disamping itu kebutuhan ABK tentu akan meningkat seiring dengan meningkatnya kebutuhan perahu saat musim panen, oleh pemilik perahu (pengusaha pelayaran maupun para pengusaha perorangan). Masalah ketersediaan tenaga kerja perikanan (khususnya ABK) yang ada di Desa Pengambengan tentu akan semakin langka, belum lagi masalah sistem bagi hasil antara pemilik perahu dan ABK luar daerah agar bisa mendatangkan mereka atau datang sebagai tenaga kerja usaha perikanan tangkap. Pada wilayah tersebut biasa-nya bermukim para nelayan yang membentuk komunitas-komunitas pedesaan. Mengingat sifat hakikat perairan disekitar wilayah pantai yang aksesnya terbuka maka sumber daya yang ter-kandung didalamnya cenderung untuk mengala- mi pengurasan, terutama di daerah perairan pantai yang penduduknya padat (Sutrisno, 2014).

Mobilitas penduduk merupakan gerak penduduk yang melintasi batas wilayah dalam periode waktu tertentu (Rustariyuni, 2013). Mobilitas yang dilakukan oleh ABK luar daerah desa Pengambengan kemungkinan adalah untuk memperoleh penghasilan yang tinggi agar pemenuhan kebutuhan hidup keluarganya terjamin pada saat ia kembali ketempat asal. Keinginan untuk mencapai status dan penghasilan yang lebih 
tinggi dari apa yang pernah dicapai oleh seseorang, merupakan impian setiap orang. Dalam penelitian yang dilakukan oleh Suherman (2009) yang berjudul "Dampak Sosial Ekonomi Pembangunan dan Pengembangan Pelabuhan Perikanan Nusantara (PPN) Pengambengan Jembrana Bali" yang bersifat studi kasus, memaparkan penelitiannya bahwa keberadaan PPN Pengambengan yang menyediakan fasilitas seperti Pusat Pengembangan Masyarakat Nelayan, Tempat Berlabuh Kapal Perikanan, Tempat Pendaratan Ikan Hasil Tangkapan, Pusat Pemasaran dan Distribusi Ikan Hasil Tangkapan, Pusat Pelaksanaan Pembinaan Mutu Hasil Perikanan, Pusat Pelaksanaan Penyuluhan dan Pengumpulan Data Perikanan dan Pusat Pelaksanaan Pengawasan Sumberdaya Ikan, sangat berdampak terhadap tingkat kesejahteraan masyarakat pantai sehingga terjadinya peningkatan usaha dan terbukanya kesempatan kerja atau lapangan pekerjaan yang baru bagi masyarakat sekitar.

\section{Metode}

Penelitian ini adalah penelitian deskriptif kualitatif dengan metode pengumpulan data pencatatan dokumen. Penelitian deskriptif adalah penelitian yang dilakukan untuk mengetahui keberadaan variabel mandiri, baik halnya satu variabel atau lebih tanpa membuat perbandingan atau dengan menghubungkan dengan variabel lainnya (variabel mandiri adalah variabel yang berdiri sendiri). Lokasi penelitian ini berada di Desa Pengambengan Kecamatan Negara Kabupaten Jembrana. Sampel dalam penelitian ini adalah seluruh ABK luar daerah yaag tersebar pada masing-masing perahu yakni 70 orang.

Jenis data yabg digunakan dalam penelitian ini adalah data primer dan data sekunder. Data primer langsung diperoleh dari responden melalui kuisioner, sedangkan untuk data sekunder berasal dari Pelabuhan Perikanan Nusantara (PPN) Pengambengan serta sumber-sumber pustaka yang ada.

Teknik pengupulan data dalam penelitian ini menggunakan observasi, wawancara, angket/kuisioner dan dokumentasi yang selanjutnya dianalisis menggunakan teknik analisis data kualitatif SPSS.

\section{Hasil dan pembahasan}

\subsection{Faktor-faktor yang mempengaruhi perilaku mobilitas ABK PPN Pengambengan}

Terdapat tiga Faktor utama yang mempengaruhi dalam terjadinya mobilitas yakni faktor pendorong dari daerah asal, faktor penarik dari daerah tujuan dan faktor rintangan.

Tabel 2.

Faktor pendorong dari daerah asal ABK PPN Pengambengan

\begin{tabular}{|c|c|c|c|c|c|}
\hline & & Frequency & Percent & Valid Percent & $\begin{array}{c}\text { Cumulative } \\
\text { Percent }\end{array}$ \\
\hline \multirow[t]{5}{*}{ Valid } & A & 2 & 2.8 & 2.9 & 2.9 \\
\hline & $B$ & 4 & 5.6 & 5.7 & 8.6 \\
\hline & C & 25 & 35.2 & 35.7 & 44.3 \\
\hline & $D$ & 39 & 54.9 & 55.7 & 100.0 \\
\hline & Total & 70 & 100 & 100.0 & \\
\hline Missing & System & & & & \\
\hline Total & & 70 & 100.0 & & \\
\hline
\end{tabular}


Berdasarkan tabel 2. dapat dilihat bahwa faktor pendorong dari daerah asal yang paling utama dari 70 responden ABK PPN Pengambengan luar daerah adalah sedikit lapangan pekerjaan di daerah asal sesuai profesi (ekonomi) berjumlah $54.9 \%$, kemudian saran dari teman/kerabat/tetangga di daearh asal 35.2\%, kemudian dorongan keluarga berjumlah 5.6\%, kemudian alasan karena tidak memiliki kerabat didaerah asal $2.8 \%$.

Tabel 3.

Faktor penarik dari daerah tujuan ABK PPN Pengambengan luar daerah

\begin{tabular}{|ll|r|r|r|r|}
\hline & & Frequency & Percent & Valid Percent & $\begin{array}{c}\text { Cumulative } \\
\text { Percent }\end{array}$ \\
\hline Valid & A & 36 & 50.7 & 51.4 & 51.4 \\
& B & 6 & 8.5 & 8.6 & 60.0 \\
& C & 4 & 5.6 & 5.7 & 65.7 \\
& D & 24 & 33.8 & 34.3 & 100.0 \\
& Total & 70 & 100 & 100.0 & \\
Missing & System & & & & \\
Total & & 70 & 100.0 & & \\
\hline
\end{tabular}

Sumber: Data Primer diolah, 2018

Berdasarkan tabel 3. dapat dilihat bahwa faktor penarik dari daerah tujuan yang paling utama dari 70 responden ABK PPN Pengambengan luar daerah adalah faktor pendapatan berjumlah $50.7 \%$, kemudian faktor peluang menjadi ABK sangat tinggi (saat musim panen ikan) $33.8 \%$, kemudian faktor biaya hidup terjangkau atau murah berjumlah 5.6\%, fasilitas yang lengkap di daerah tujuan berjumlah $8.5 \%$.

Tabel 4 .

Analisis faktor rintangan ABK PPN Pengambengan luar daerah melakukan mobilitas

\begin{tabular}{|ll|r|r|r|r|}
\hline & Frequency & Percent & Valid Percent & $\begin{array}{c}\text { Cumulative } \\
\text { Percent }\end{array}$ \\
\hline Valid & a & 49 & 69.0 & 70.0 & 70.0 \\
& b & 8 & 11.3 & 11.4 & 81.4 \\
& C & 3 & 4.2 & 4.3 & 85.7 \\
& d & 10 & 14.1 & 14.3 & 100.0 \\
& Total & 70 & 100 & 100.0 & \\
Missing & System & & & & \\
Total & & 70 & 100.0 & & \\
\hline
\end{tabular}

Sumber: Data Primer diolah, 2018 
Berdasarkan tabel 4. dapat dilihat bahwa faktor rintangan utama yang menjadi penghalang ABK PPN Pengambengan luar daerah melakukan mobilitas dari 70 responden adalah jarak berjumlah $69,0 \%$, kemudian faktor lainnya yang mempengaruhi berjumlah 14,1\% kemudianbiaya berjumlah 11,3\%, kemudian saranaprasana transportasi yang minim berjumlah $4,2 \%$.

\subsection{Karakteristik ABK PPN Pengambengan Pola sebaran daerah asal ABK PPN \\ Pengambengan}

Karakteristik ABK PPN Pengambengan luar daerah yakni meliputi usia, stattus pernikahan serta profesi sebelum menjadi ABK.

Tabel 5.

Data rentang usia ABK luar daerah

\begin{tabular}{|l|l|c|c|}
\hline No & \multicolumn{1}{|c|}{ Rentang Usia } & Jumlah & Persentase \\
\hline$(1)$ & \multicolumn{1}{|c|}{$(2)$} & $(3)$ & $(4)$ \\
\hline 1 & $10-19$ tahun & 6 & $8,6 \%$ \\
\hline 2 & $20-29$ tahun & 31 & $44,3 \%$ \\
\hline 3 & $30-39$ tahun & 22 & $31,4 \%$ \\
\hline 4 & $40-49$ tahun & 7 & $10,0 \%$ \\
\hline 5 & $50-39$ tahun & 3 & $4,3 \%$ \\
\hline 6 & 60 keatas & 1 & $1,4 \%$ \\
\hline & Jumlah total & 70 & $100 \%$ \\
\hline
\end{tabular}

Berdasarkan tabel 5. dapat diketahui bahwa kisaran usia ABK PPN Pengambengan luar daerah yang paling banyak ada pada rentang usia 20 - 29 tahun sebanyak 31 orang atau $44.3 \%$, kemudian rentang usia 30 - 39 tahun sebanyak 22 orang atau $31.4 \%$, kemudian rentang usia 40 - 49 tahun sebanyak 7 orang atau $10.0 \%$, kemudian rentang usia 10 - 19 tahun sebanyak 6 orang atau $8.6 \%$, kemudian rentang usia 50 - 59 tahun sebanyak 3 orang atau $4.3 \%$ dan jumlah paling sedikit yakni rentang usia 60 tahun keatas 1 orang atau $1.4 \%$.

Tabel 6.

Profesi sebelum menjadi ABK PPN Pengambengan

\begin{tabular}{|ll|r|r|r|r|}
\hline & & & & \multicolumn{2}{c|}{$\begin{array}{c}\text { Cumulative } \\
\text { Percent }\end{array}$} \\
\hline Valid & a & 49 & 69.0 & 70.0 & 70.0 \\
& b & 8 & 11.3 & 11.4 & 81.4 \\
& c & 3 & 4.2 & 4.3 & 85.7 \\
& d & 10 & 14.1 & 14.3 & 100.0 \\
& Total & 70 & 100 & 100.0 & \\
Missing & System & & & & \\
Total & & 70 & 100.0 & & \\
\hline
\end{tabular}


Berdasarkan tabel 4.9. dapat diketahui bahwa sebagian besar profesi responden sebelum menjadi ABK PPN Pengambengan yakni berprofesi sebagai Nelayan dengan jumlah 69.0\%, berprofesi sebagai pedagang dengan jumlah $14.1 \%$, kemudian berprofesi sebagai Buruh dengan jumlah $11.3 \%$, kemudian kemudian berprofesi sebagai Petani $4.2 \%$.

Tabel 7.

Status pernikahan ABK PPN Pengambengan luar daerah

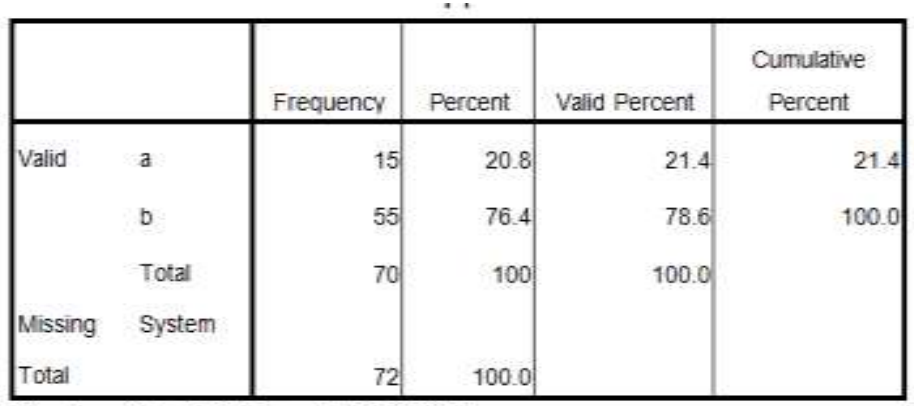

Sumber: Data Primier diolah, 2018

Berdasarkan tabel 7. dapat diketahui bahwa 55 orang dari 70 responden atau $76.4 \%$ bertsatus menikah sedangkan sisanya yakni 15 orang responden atau $20.8 \%$ berstatus belum menikah.

\subsection{Pola persebaran ABK PPN Pengambengan luar daerah}

Setiap arus mobilitas menimbulkan arus balik sebagai penggantinya atau menurut Revenstein tiap arus mobilitas akan menimbulkan arus balik. Adapun intensitas mobilitas kembali ke daerah asal (intensitas yang dimaksut di ukur dengan jarak serta lama tinggal didaerah tujuan).

Tabel 8.

Intensitas mobilitas ABK luar daerah kembali ke daerah asal

\begin{tabular}{|l|l|c|c|}
\hline No & \multicolumn{1}{|c|}{ Intensitas Mobilitas } & Jumlah & Persentase \\
\hline$(1)$ & \multicolumn{1}{|c|}{$(2)$} & $(3)$ & $(4)$ \\
\hline 1 & 4 kali perbulan & 0 & $0,0 \%$ \\
\hline 2 & 3 kali perbulan & 0 & $0,0 \%$ \\
\hline 3 & 2 kali perbulan & 3 & $4,3 \%$ \\
\hline 4 & 1 kali perbulan & 48 & $68,6 \%$ \\
\hline 5 & 1 kali per 2 bulan & 12 & $17,1 \%$ \\
\hline 6 & 1 kali per 3 bulan & 1 & $8,6 \%$ \\
\hline 7 & 6 bulan 1 kali & 70 & $1,4 \%$ \\
\hline & Jumlah total & & $100 \%$ \\
\hline
\end{tabular}


Berdasarkan tabel 8. dapat diketahui bahwa intensitas mobilitas dari 70 responden $A B K$ luar daerah yang ada, sebanyak 48 orang atau $68,6 \%$ akan melakukan mobilitas kembali ke daerah asal selama 1 kali perbulan, kemudian 12 orang atau 17,1 $\%$ akan melakukan mobilitas kembali ke daearh asal selama 1 kali per 2 bulan, 6 orang atau 8,6 \% akan melakukan mobilitas kembali ke daerah asal selama 1 kali per 3 bulan, 3 orang atau 4,3\% akan melakukan mobilitas kembali ke daerah asal selama 2 kali perbulan dan 1 orang atau 1,4\% akan melakukan mobilitas kembali ke daerah asal selama 2 kali pertahun.

\subsection{Faktor pendorong dari daerah asal ABK PPN Pengambengan}

Daya dorong dari daerah asal yang mempengaruhi seseorang melakukan mobilitas penduduk adalah faktor-faktor yang ada di daerah asal. Faktor pendorong merupakan kekurangan dari daerah tersebut, sehingga banyak masyarakat yang meninggalkan daerah asalnya menuju ke daerah lain. Misalnya, kepemilikan lahan pertanian yang sempit di daerah asal, pendapatan yang rendah di daerah asal, dan sulitnya mencai pekerjaan di daerah asal.

Adapun hasil penelitian menunjukkan bahwa faktor pendorong dari daerah asal yang paling utama yakni sedikit lapangan pekerjaan di daerah asal sesuai profesi dengan jumlah $67.1 \%$. Hal ini senada dengan berbagai hasil penelitian yang menunjukkan bahwa faktor ekonomi merupakan alasan kuat yang menjadi faktor pendorong utama sebagian besar pelaku mobilitas untuk bermobilitas.

\subsection{Faktor penarik dari daerah tujuan ABK PPN Pengambengan}

Selain ada faktor pendorong dari daerah asal yang menyebabkan penduduk melakukan mobilitas, maka ada faktor penarik dari daerah tujuan yang menyebabkan penduduk berkeinginan melakukuan mobilitas. Adapun faktor penarik dari daerah tujuan yang paling utama adalah alasan dimana daerah tujuan menyediakan pendapatan lebih tinggi dari pada daerah asaldengan jumlah 51,4 \%. Hal ini dapat terjadi karena pada dasarnya mobilitas yang dilakukan oleh ABK merupakan suatu reaksi atas kesempatan ekonomi pada suatu wilayah. Mobilitas yang dilakukan ABK juga merupakan refleksi perbedaan pertumbuhan dan ketidakmerataan fasilitas pembangunan antara satu daerah dengan daerah lainnya.

\subsection{Faktor rintangan ABK PPN Pengambengan}

Selain faktor pendorong dari daerah asal dan faktor penarik dari daerah tujuan, faktor rintangan juga dapat menghalangi niat ABK untuk melakukan mobilitas ke daerah tujuan (PPN Pengambengan). Faktor rintangan yang paling utama adalah jarak dengan jumlah $69 \%$ dan yang paling sedikiat sarana-prasarana transportasi yang minim. Faktor jarak merupakan faktor penting dalam penentuan arah, setidak-tidaknya dalam penentuan bentuk mobilitas Penduduk. Daerah tujuan yang berjarak dekat dengan 
daerah asal cukup di lakukan secara ulang-alik (Commuting), sebaliknya daerah tujuan yang berjarak jauh dari daerah asal akan dilakukan secara sirkuler bahkan dilakukan secara permanen.

\subsection{Rentang usia ABK PPN Pengambengan}

Motivasi penduduk untuk melakukan mobilitas dipahami sebagai harapan untuk meningkatkan kondisi perekonomian rumah tangga yang ditinggalkan. Untuk itu mereka berusaha untuk menekan pengeluaran selama berada di daerah tujuan. Misalnya dengan tinggal di tempat dengan sewa yang murah, bahkan menumpang pada keluarga atau para pelaku mobilitas sebelumnya.Adapun karakteristik ABK PPN Pengambengan luar daerah dilihat dari usia didominasi oleh rentang usia 20-29 tahun dengan jumlah persentase $44.3 \%$ dimana usia ini merupakan usia produktif sedangkan usia yg paling sedikit adalah $1.4 \%$.

\subsection{Status Pernikahan}

Peningkatan status sosial ke tingkat yang lebih tinggi dapat dilakukan melalui pernikahan (A. Samad Usman) Karakteristik dilihat dari status pernikahan didominasi oleh ABK yang sudah menikah dengan jumlah persentase $76 \%$ sedangkan yang belum menikah $20.8 \%$.

\subsection{Intensitas pulang kedaerah asal}

Mobilitas merupakan pergerakan penduduk yang bersifat sementara dan ada niatan dari pelaku mobilitas untuk tinggal dalam jangka waktu tertentu di daerah lain. Pada umumnya keinginan untuk kembali kedaerah asal tergantung kepada besar kecilnya kepuasan yang di dapat di daerah tujuan (kota). Adapun arus balik atau intensitas mobilitas kembali ke daerah asal yang dilakukan oleh ABK dalam kurung waktu 6 (enam) bulan, paling banyak dilakukan oleh responden sebayak satu kali perbulan yakni dengan jumlah $68.6 \%$ atau sebanyak 48 orang. Atau setidaknya ABK PPN Pengambengan luar daerah dalam kurung waktu 6 (enam) bulan melakukan arus balik sebanyak 6 (enam) kali.

\subsection{Pola sebaran daerah asal ABK PPN Pengambengan}

Pola perpindahan penduduk telah diwarnai oleh mobilitas permanen (menetap di daerah tujuan) dan non permanen (yang tidak menetap di daerah tujuan) dengan arah yang berubah. Berkaitan dengan pola sebaran daerah asal ABK PPN Pengambengan luar daerah adalah didominasi dari derah asal Kabupaten Banyuwangi dengan jumlah $37.1 \%$ atau 26 orang ABK. Apabila dilihat dari pola sebaran daerah asal ABK, hal ini dapat terjadi karena adanya keterkaitan antara para plaku mobilitas dengan situasi daerah yang dipilih sebagai tujuan yakni jarak yang dekat. Secara alamiah dalam memilih daerah tujuan, para pelaku mobilitas cenderung memilih daerah yang terdekat dari daerah asal, sedangkan menurut teori berantai proses mobilitas yang dilakukan oleh ABK ini dapat terjadi karena tidak terlepas dari kaitannya dengan eksistensi famili atau kawan yang telah tinggal terlebih dahulu di daerah tujuan tersebut.

\section{Simpulan dan saran}


Berdasarkan hasil dari penelitian dan hasil wawancara dengan ABK PPN Pengambengan luar daerah maka dapat disimpulkan sebagai berikut (1) Faktor penyebab para mobilisan meninggalkan daerah asal ada dua yaitu faktor pendorong dan penarik, faktor pendorong utama yang mempengaruhi ABK luar daerah adalah faktor ekonomi, dimana paling banyak responden menyatakan bahwa sedikit lapangan pekerjaan didaerah asal. Kemudian faktor penarik dari daerah tujuan yang mempengaruhi ABK luar daerah melakukan mobilitaskarena alasan bahwa peluang menjadi ABK sangat tinggi di daerah tujuan. Sedangkan faktor yang menghalangi niat ABK untuk melakukan mobilitas ke Desa Pengambengan adalah jarak (2) Perilaku mobilitas ABK luar daerah (1) dilihat dari karakteristiknya memiliki usia yang sangat produktif dengan rentang usia didominasi oleh usia 29 - 30 tahun, sedangkan untuk status perkawainan didominasi oleh ABK yang telah menikah.(2)Sedangkanintensitas ABK untuk kembali kedaerah asal paling banyak dilakukan dalam kurun waktu satu kali perbulan (3) Pola sebaran mobilitas ABK PPN luar daerah sebagian besardari daerah asalKabupaten Banyuwangi, sedangkan intensitas kembali ke daerah asal dari seluruh ABK PPN paling banyak dilakukan selama satu bulan sekali

Berdasarkan penelitian yang dapat disarankan adalah Intensitas mobilitas kembali ke daerah asal yang sering dilakukan oleh ABK luar daerah tergolong sangat tinggi yakni selama rentang waktu satu kali perbulan, disamping itu juga diketahui jarak merupakan faktor yang menghalangi niat ABK. Oleh sebab itu sebaiknya pemerintah setempat dapat menyediakan tempat tinggal khusus bagi ABK PPN Pengambengan luar daerah, agar intensitas mobilitas ABK dapat menurun.

\section{Daftar Rujukan}

Edy, M. Y. (2017). Paceklik Ikan Runtuhkan Ekonomi Nelayan Jembrana. Retrieved from http://bali.antaranews.com/berita/124079/paceklik/ikan/runtuhkan/ekonomi/nelayan/j embrana

Masyhuri. (2014). Pembiayaan Usaha Perikanan Tangkap dan Mobilitas Sosial Nelayan. Masyarakat Dan Budaya, 16(1).

Retnowati, E. (2011). Kajian Indonesia Dalam Pusaran Kemiskinan Struktural (Prespektif Sosial, Ekonomi, dan Hukum). Prespektif, 16(3).

Rustariyuni, S. D. (2013). FAKTOR-FAKTOR YANG MEMPENGARUHI MINAT MIGRAN MELAKUKAN MOBILITAS NON PERMANEN KE KOTA DENPASAR. Piramida, 9(2), 95-104.

Santara, A. G. (2014). Peralatan Keselamatan Kerja Pada Perahu Slerek di PPN Pengambengan, Kabupaten Jembrana, Bali. IPTEKS PSP, 1, 53-68.

Suherman, A. D. dan A. (2009). Dampak Sosial Ekonomi Pembangunan dan Pengembangan Pelabuhan Perikanan Nusantara (PPN) PengambenganJembrana Bali. Saintek Perikanan, $4(2)$.

Sutrisno, E. (2014). IMPLEMENTASI PENGELOLAAN SUMBER DAYA PESISIR BERBASIS PENGELOLAAN WILAYAH PESISIR SECARA TERPADU UNTUK KESEJAHTERAAN NELAYAN. $14(1)$.

Suyanto, B. (2011). Mekanisme Survival, Identifikasi Kebutuhan dan Pemberdayaan Nelayan Miskin dalam Masa Kritis Akibat Kenaikan Harga BBM. 24(1), 74-83.

Tain, A. (2011). PENYEBAB KEMISKINAN RUMAH TANGGA NELAYAN DI WILAYAH TANGKAPLEBIH JAWATIMUR. Humanity, 7(1), 01-10.

Triarso, I. (2012). POTENSI DAN PELUANG PENGEMBANGAN USAHA PERIKANAN TANGKAP DI PANTURA JAWA TENGAH. Saintek Perikanan, 8(1). 